\title{
On the Valuation and Analysis of Risky Debt: A Theoretical Approach Using a Multivariate Extension of the Merton Model
}

\author{
Edwin O. Fischer, Lisa-Maria Kampl, Ines Wöckl
}

Working Paper 2019-02

September 8, 2019

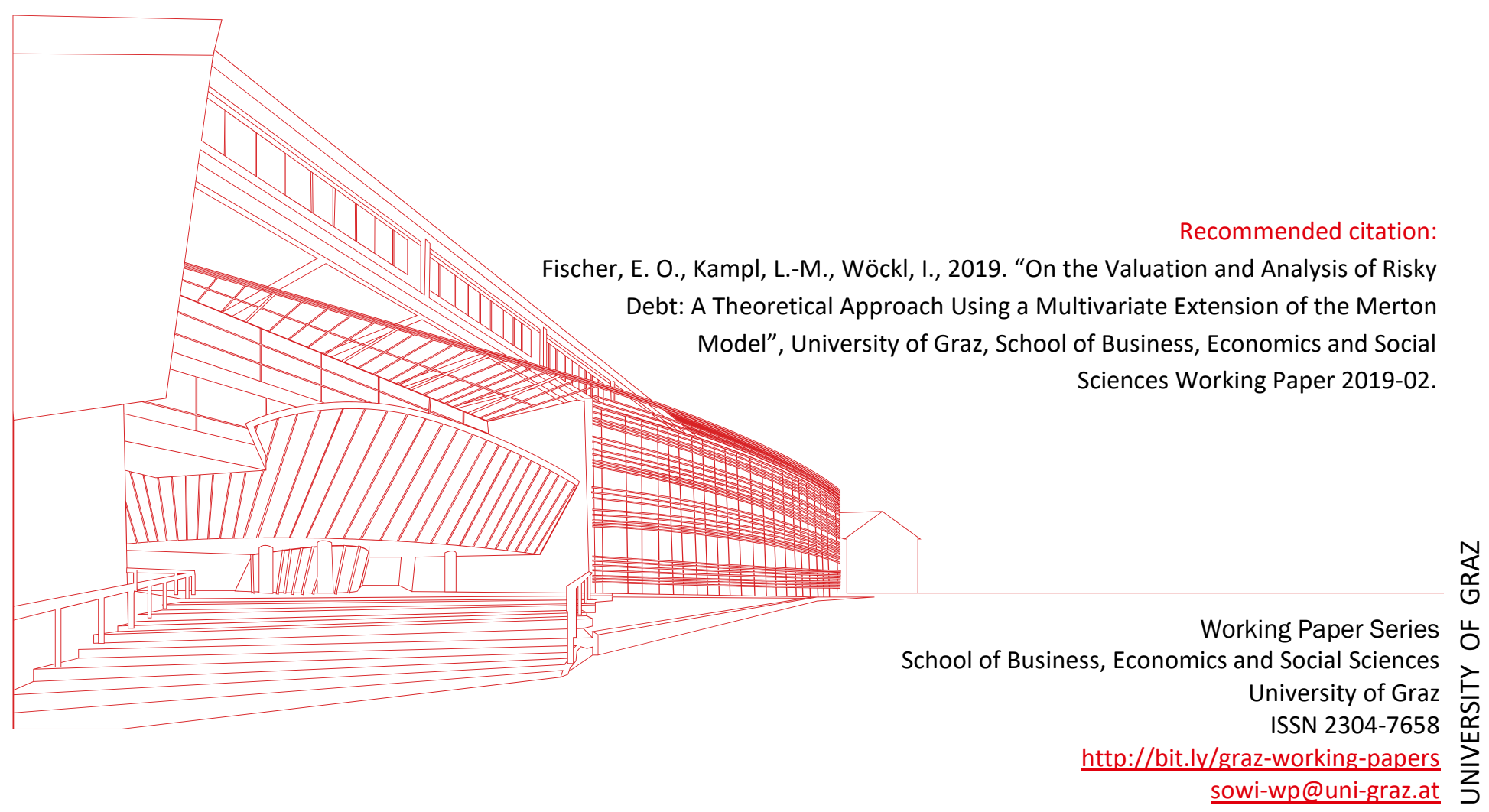




\title{
On the Valuation and Analysis of Risky Debt: A Theoretical Approach Using a Multivariate Extension of the Merton Model
}

\author{
Edwin O. Fischer \\ University of Graz, Institute of Finance \\ Lisa-Maria Kampl \\ University of Graz, Institute of Finance \\ Ines Wöckl \\ University of Graz, Institute of Finance \\ Corresponding author: +43(316)380-3514, ines.woeck।@uni-graz.at
}

\section{Working Paper 2019-02}

September 8, 2019

\section{Abstract}

We contribute to the literature on the valuation of risky debt by providing three nested multivariate extensions of the standard Merton model. First, we lay forth an approach to pricing risky debt irrespective of its interest payment structure and the specified redemption agreement. Second, we propose a technique for valuing multiple debt instruments within the same firm. Third, we provide an approach for pricing one or more debt instruments with continuous dividend payments.

Keywords: risky debt, debt valuation, debt analysis, expected yield

\section{JEL:} G21, G31, G32

Any opinions expressed herein are those of the author(s) and not those of the Faculty of Social and Economic Sciences. Working Papers receive only limited review and often represent preliminary work. They are circulated to encourage discussion. Citation of such a paper should account for its provisional character. A revised version may be available directly from the author.
Working Paper Series School of Business, Economics and Social Sciences University of Graz ISSN 2304-7658 http://bit.ly/graz-working-papers sowi-wp@uni-graz.at 


\title{
On the Valuation and Analysis of Risky Debt: A Theoretical Approach Using a Multivariate Extension of the Merton Model
}

\author{
Edwin O. Fischer ${ }^{*}$ \\ Lisa-Maria Kampl ${ }^{*}$ \\ Ines Wöckl ${ }^{*} \dagger$
}

September 2019

\footnotetext{
* University of Graz, Institute of Finance, Universitätsstrasse 15/G2, 8010 Graz, Austria.

† Corresponding author: Tel. +43 (0) 316380 3514, E-mail ines.woeckl@uni-graz.at.
} 


\title{
On the Valuation and Analysis of Risky Debt: A Theoretical Approach Using a Multivariate Extension of the Merton Model
}

\begin{abstract}
We contribute to the literature on the valuation of risky debt by providing three nested multivariate extensions of the standard Merton model. First, we lay forth an approach to pricing risky debt irrespective of its interest payment structure and the specified redemption agreement. Second, we propose a technique for valuing multiple debt instruments within the same firm. Third, we provide an approach for pricing one or more debt instruments with continuous dividend payments.
\end{abstract}

Keywords: risky debt, debt valuation, debt analysis, expected yield

JEL Codes: G21, G31, G32 


\section{Introduction}

With his seminal paper "On the Pricing of Corporate Debt: The Risk Structure of Interest Rates" Robert C. Merton laid the foundation for the valuation and analysis of risky debt. The approach has become known as the Merton model and is nowadays widely used when analyzing and pricing risky corporate debt.

The Merton model applies the insights of the well-known Black and Scholes (1973) option pricing model to the valuation of corporate debt. It focuses primarily on the analysis of zero-coupon debt and is based on a few general assumptions. First of all, it is assumed that the value of the firm (i.e., the total assets), $V_{T}$, merely consist of two classes of claims. On the one hand, the firm has a single, homogenous class of debt in the shape of a zero-coupon discount bond where the payment of the nominal value Nom is promised at maturity $T$. On the other hand, it has equity which is seen as a residual claim. The total assets are distributed logarithmically normally and can be described by the diffusion-type stochastic process

$$
\frac{d V}{V}=\mu_{V} d t+\sigma_{V} d z
$$

where $\mu_{V}$ refers to the drift. $\sigma_{V}$ is the volatility of the return on the firm per unit time which is assumed to be constant. It is assumed that the term structure is flat, so also the risk-free interest rate $r$ is constant. There are no taxes, transaction costs, or dividends, and the investors are price takers. Furthermore, securities are freely divisible and trading in the assets takes place continuously in time.

Under these assumptions, the firm's equity at maturity can be seen as a European call option written on the underlying asset $V_{T}$ with exercise price Nom and maturity $T$

$$
E_{T}=\left\{\begin{array}{lr}
0 & \text { if } V_{T}<N o m \\
V_{T}-\text { Nom } & \text { if } V_{T} \geq N o m
\end{array}\right\}
$$

Since the value of the debt can be written as the value of the total assets less the value of the equity, it follows that

$$
D_{T}=\left\{\begin{array}{ll}
V_{T} & \text { if } V_{T}<\text { Nom } \\
\text { Nom } & \text { if } V_{T} \geq \text { Nom }
\end{array}\right\}
$$

This implies that the value of the firm's debt can be seen either as a long position in the firm's asset in combination with a short position in a call on the same, or as a long position in a risk-free zero-coupon bond combined with a short put on the assets.

Following Merton (1974), the firm's equity and debt at time $t=0$ can be expressed as

$$
E_{0}=V_{0} \cdot N\left(d_{1}\right)-N o m \cdot e^{-r \cdot T} \cdot N\left(d_{2}\right)
$$

and

$$
D_{0}=V_{0} \cdot\left[1-N\left(d_{1}\right)\right]+N o m \cdot e^{-r \cdot T} \cdot N\left(d_{2}\right),
$$


respectively, where

$$
\begin{gathered}
d_{1}=\frac{\ln \frac{V_{0}}{N o m}+\left(r+\frac{\sigma_{V}^{2}}{2}\right) T}{\sigma_{V} \cdot \sqrt{T}}, \\
d_{2}=\frac{\ln \frac{V_{0}}{N o m}+\left(r-\frac{\sigma_{V}^{2}}{2}\right) T}{\sigma_{V} \cdot \sqrt{T}}=d_{1}-\sigma_{V} \cdot \sqrt{T},
\end{gathered}
$$

and $N(\cdot)$ denotes the standard normal cumulative distribution function

We rearrange equation (1) to better illustrate the composition of the debt.

$$
D_{0}=N o m \cdot e^{-r \cdot T}-\left[N o m \cdot e^{-r \cdot T}-V_{0} \cdot \frac{N\left(-d_{1}\right)}{N\left(-d_{2}\right)}\right] \cdot N\left(-d_{2}\right)
$$

The first term on the righthand side of equation (2) is the long position in the risk-free bond while the second term is equal to the expected discounted loss. The latter can be expressed as the product of the discounted loss given default (term in parenthesis) and the risk-neutral probability of default,

$$
P D=N\left(-d_{2}\right) .
$$

The probability of default is the probability that the firm will be unable to satisfy some or all of the requirements specified in the debt specifications (i.e., the bond indenture).

Since its publication in the 1970s, the Merton model has had significant influence on the scientific literature as well as in practice. In practical applications, however, the value of the assets, $V_{0}$, and the volatility of assets, $\sigma_{V}$, must be proxied from observable variables, since they themselves are not directly observable. Instead, they are estimated iteratively using the value of the equity and the equity volatility which are both observable for listed firms. The value of the equity is derived from the share price, $S_{0}$, multiplied by the number of shares issued. The equity volatility, $\sigma_{E}$, is determined historically or implied from the market.

The traditional Merton framework has a number of limitations, many of which have been addressed in various refinements and extensions. ${ }^{3}$ One shortcoming of the Merton model is, for example, the unrealistic assumption that the firm can only default at its debt maturity date. In reality, firms can default long before their assets are exhausted. Black and Cox (1976) were the first to develop a model with a more realistic default condition by allowing default to occur prior to the debt's maturity. Their model uses methods for pricing barrier options and default occurs when the value of the firm's assets falls below a specified time-dependent threshold. Additionally, they

\footnotetext{
${ }^{3}$ For a survey of the Merton model and its extensions see Bohn (2000) or Sundaram and Das (2009), for instance.
} 
provide an analysis of the effects of subordination arrangements and restrictions on the financing of interest and dividend payments on the valuation process. In the Black and Cox (1967) approach the threshold (i.e., the bankruptcy trigger or killing price) is determined exogenously. Leland (1994) and Anderson and Sundaresan (1996), who also study the valuation of multiperiod debt contracts under uncertainty, endogenize the lower reorganization boundary, on the other hand. In our approach we follow the latter and determine the killing prices endogenously.

A second limiting aspect of the Merton model is the assumption that the interest rate is constant. In reality, the value of debt is significantly influenced by interest rate risk. As a result, models with stochastic interest rates have been developed in an attempt to improve the quality of the valuations generated. ${ }^{4}$ Kim et al. (1993) develop a contingent claims valuation models with stochastic interest rates for corporate bonds that additionally incorporates the possibility of early default. Like Merton they model the firm's debt as a single issue of debt outstanding and set a constant default boundary. Longstaff and Schwartz (1995) also provide a simple approach to valuing risky corporate debt that incorporates both default risk and interest rate risk. They derive simple closed-form valuation expressions for fixed and floating rate debt and assume a constant default boundary. The corporate bond valuation model by Briys and de Varenne (1997) also takes both early default and interest rate risk into account. However, they incorporate a stochastic default boundary. In this paper, we follow the original Merton (1974) approach and assume the interest rate is constant. The term "risky" is therefore restricted to mean possible gains or losses owing to (unanticipated) changes in the probability of default. The definition does not encompass gains or losses resulting from (unanticipated) changes in interest rates.

Furthermore, the assumption that the debt of the firm can be described by a single risky zero-coupon bond can be seen as a shortcoming of the Merton model. This assumption significantly reduces its relevance to pricing actual corporate debt, since firms will generally have more specific contractual features regarding their debt. When a firm's debt incorporates interest payments and specific, potentially even complicated, repayment agreements, the valuation poses more of a challenge. This is due to the fact that if the firm defaults on a single interest payment, all subsequent payments (interest and principal repayment) are also defaulted on. Geske $(1977)^{5}$ proposes an extension of the Merton model that enables pricing single risky discrete coupon bonds with finite maturity using the multivariate normal distribution. The model is based on a technique for valuing compound options. Fischer et al. (2000) present a model based on Geske $(1977,1979)$ that allows for the valuation of loan guarantees regardless of the terms and conditions of interim payments. Similarly, our model allows for the valuation of any kind of debt instrument, irrespective of its interest payment structure and the specified redemption agreement.

Finally, in the Merton framework as well as its extensions the firm's debt is generally given in the shape of a single debt instrument. In reality, firms will often have a debt portfolio consisting of multiple different debt instruments. Since the default of the debtor in one debt instrument has immediate consequences for all other debt

\footnotetext{
${ }^{4}$ For a detailed overview on articles that incorporate both default risk and interest rate risk see Longstaff and Schwartz (1995).

${ }^{5}$ See also Geske and Johnson (1984).
} 
instruments in the debtor's portfolio, the instruments cannot be valued independently. We propose a technique for valuing single debt instruments when multiple debt instruments are present within the same firm that takes into account these interdependencies.

In summary, we address all aforementioned limitations of the standard Merton model and provide a comprehensive model for the valuation of single debt instruments as well as debt portfolios irrespective of the interest and repayment modalities specified in the instruments' indentures. Additionally, our model enables the incorporation of continuous dividend payments into the valuation.

The paper is organized as follows. Section 2 describes our model for the valuation of single debt instruments depending on their different repayment agreements. We also provide a general closed-form valuation formula that can be used to value debt instruments with any kind of interest payment structure and repayment agreement. In Section 3, we adapt our valuation model to include the scenario where a single firm has multiple debt instruments. We show how the presence of other debt instruments influences the valuation of each respective debt instrument. Section 4 extends the multiple debt instrument scenario to incorporate continuous dividend payments to the equity holders. We conclude the paper in Section 5, which summarizes the main findings and suggests some avenues of further research.

\section{Different Repayment Agreements}

As mentioned above, the Merton (1974) analysis is simplified considerably by the assumption that the firm holds only one zero-coupon debt. This reduces its applicability to valuing actual debt which often resembles bonds with more complicated payback agreements. Geske (1977) derives closed-form valuation expressions to determine the value of a firm when the debt takes on the shape of risky coupon bonds. We generalize his coupon bond approach in order to be able to value risky debt for any kind of arrangement regarding the principal repayment, lump sum repayment, annuity repayment, and constant principal repayment.

\subsection{Valuation Setup}

Our considerations are based on a range of assumptions following Merton (1974) and Geske (1977). We assume that the firm has two classes of claims; debt and equity. In our first extension of the basic model we assume the firm has exactly one debt instrument in addition to its equity. This debt instrument can have any kind of interest and principal payment structure. Also, each payment to the debtholders is refinanced through new external capital, either using equity from existing or new equity holders or using debt. Additionally, we assume that changes in the value of the firm follow a stationary random walk, that the firm pays no dividends, and that investors agree about the volatility of assets, $\sigma_{V}$.

Under these assumptions, if the face value of a risky debt instrument at $t=0$ is Nom, then the outstanding debt at $t=1, \ldots, T-1$ is 


$$
N_{\text {om }}=\text { Nom }_{t-1}-P_{t}=N o m-\sum_{\tau=1}^{t} P_{\tau}
$$

where $P_{t}$ is the proportion of the nominal value repaid at time $t, N o m_{T}=0$, and $P_{T}=$ $N_{T-1}$. For a fixed nominal interest rate, $i_{n o m}$, the interest payments in each period $t=1, \ldots, T$ are

$$
I_{t}=i_{n o m} \cdot \operatorname{Nom}_{t-1}
$$

Since principal repayments reduce the value of the outstanding debt, the Merton formulas in their original form cannot be used to price the equity or the risky debt of the firm. This is the case because the equity must now be interpreted as a compound option rather than a simple European call option. The equity holders have two options in each period $t$. They can either pay the interest and principal repayments due (which is equivalent to buying a new option), or they can refuse to make the required payments and declare bankruptcy (which is equivalent to letting the option expire worthlessly).

\subsection{Valuation Basics}

The value of the equity at maturity $T$ is zero if the interest and principal payments cannot be made. Otherwise, it equals the value of total assets less the interest payments and the principal repayments.

$$
E_{T}=\left\{\begin{array}{cc}
0 & V_{T} \leq I_{T}+P_{T} \\
V_{T}-\left(I_{T}+P_{T}\right) & V_{T}>I_{T}+P_{T}
\end{array}\right.
$$

This is analogous to a call on the value of the firm, $V_{T}$, with $I_{T}+P_{T}$ as the strike price.

At time $(T-1)^{+}$, momentarily after the final interest and principal payments, the value of the equity can be derived using the Black/Scholes formula

$$
E_{(T-1)^{+}}=V_{T-1} \cdot N\left(h_{1}\right)-\left(I_{T}+P_{T}\right) \cdot e^{-r} \cdot N\left(h_{2}\right)
$$

where

$$
h_{1}=\frac{\ln \frac{V_{T-1}}{I_{T}+P_{T}}+r+\frac{\sigma_{V}^{2}}{2}}{\sigma_{V}}
$$

and

$$
h_{2}=h_{1}-\sigma_{V}
$$

In consequence, the value of the risky debt at time $(T-1)^{+}$is

$$
D_{(T-1)^{+}}=V_{T-1} \cdot\left(1-N\left(h_{1}\right)\right)+\left(I_{T}+P_{T}\right) \cdot e^{-r} \cdot N\left(h_{2}\right) .
$$

The value of the equity just before the final payment is 


$$
E_{(T-1)^{-}}=\left\{\begin{array}{cc}
0 & V_{T-1} \leq V_{T-1}^{*} \\
E_{(T-1)^{+}}-\left(I_{T-1}+P_{T-1}\right) & V_{T-1}>V_{T-1}^{*}
\end{array}\right.
$$

where $E_{(T-1)^{+}}$is taken from equation (3). When it is assumed that all payments are refinanced with equity this is analogous to issuing new equity. $V_{T-1}^{*}$ represents the killing price, or bankruptcy trigger, which is the critical value of the firm at $t=T-1$ where the value of the equity at $(T-1)^{-}$is just as large as the interest and principal payments that are due at $t=T-1$.

$$
E_{T-1}\left(V_{T-1}^{*}\right)=I_{T-1}+P_{T-1}
$$

This killing price is set by the equity holders in such a way that it is ensured that the value of the equity remains non-negative immediately after the promised interest and principal payments are made (i.e., at time $(T-1)^{+}$). If the value of the equity does become negative, the shareholders will declare bankruptcy and transfer the value of the total assets to the debtholders.

One period earlier still, at time $(T-2)^{+}$, the value of the equity is

$$
\begin{gathered}
E_{(T-2)^{+}}=V_{T-2} \cdot N_{2}\left(h_{1}^{1}, h_{1}^{2} ; \rho_{2}\right)-\left(I_{T}+P_{T}\right) \cdot e^{-2 \cdot r} \cdot N_{2}\left(h_{2}^{1}, h_{2}^{2} ; \rho_{2}\right)- \\
\left(I_{T-1}+P_{T-1}\right) \cdot e^{-r} \cdot N\left(h_{2}^{1}\right)
\end{gathered}
$$

where $N_{2}($.$) is the bivariate cumulative standard normal distribution,$

$$
\begin{aligned}
h_{1}^{1}= & \frac{\ln \frac{V_{T-2}}{V_{T-1}^{*}}+r+\frac{\sigma_{V}^{2}}{2}}{\sigma_{V}} \\
h_{2}^{1}= & h_{1}^{1}-\sigma_{V} \\
h_{1}^{2}= & \frac{\ln \frac{V_{T-2}}{I_{T}+P_{T}}+\left(r+\frac{\sigma_{V}^{2}}{2}\right) \cdot 2}{\sigma_{V} \cdot \sqrt{2}} \\
h_{2}^{2} & =h_{1}^{2}-\sigma_{V} \cdot \sqrt{2}
\end{aligned}
$$

and

$$
\varrho_{2}=\left(\begin{array}{cc}
1 & \sqrt{1 / 2} \\
0 & 1
\end{array}\right)
$$

is the correlation matrix.

In general, the value of the equity at $(T-s)^{+}$for $s=1, \ldots, T$ as a function of the total assets $V_{T-S}$ can be calculated using

$$
\begin{aligned}
E_{(T-s)^{+}} & =V_{T-s} \cdot N_{s}\left(h_{1}^{1}, \ldots, h_{1}^{s} ; \rho_{s}\right) \\
& -\sum_{t=0}^{s-1}\left(I_{T-t}+P_{T-t}\right) \cdot e^{-r \cdot(s-t)} \cdot N_{s-t}\left(h_{2}^{1}, \ldots, h_{2}^{s-t} ; \rho_{s-t}\right)
\end{aligned}
$$


where $N_{S}($.$) is the cumulative standard normal distribution of dimension s$ and $\tau=$ $1, \ldots, T$,

$$
\begin{aligned}
h_{1}^{\tau}= & \frac{\ln \left(\frac{V_{T-s}}{V_{T-s+\tau}^{*}}\right)+\left(r+\frac{\sigma_{V}^{2}}{2}\right) \cdot \tau}{\sigma_{V} \cdot \sqrt{\tau}} \\
h_{2}^{\tau}= & h_{1}^{\tau}-\sigma_{V} \cdot \sqrt{\tau}
\end{aligned}
$$

and

$$
\rho_{s}=\left\langle\rho_{\tau_{1}, \tau_{2}}\right\rangle= \begin{cases}1 & \text { if } \tau_{1}=\tau_{2}, \tau_{1}=1, \ldots, \tau, \tau_{2}=1, \ldots, \tau \\ \sqrt{\tau_{1} / \tau_{2}} & \text { if } \tau_{1}<\tau_{2}, \tau_{1}=1, \ldots, \tau, \tau_{2}=1, \ldots, \tau \\ 0 & \text { else. }\end{cases}
$$

When $s=T$, equation (6) reflects the value of the equity at $t=0$.

The killing prices, $V_{\tau}^{*}$, are determined following Fischer et al. (2000) using a reverse bootstrapping technique from $t=T$ to $t=1$ by ensuring that the value of the equity immediately after the interest and principal payments fulfills the following condition for each $\tau=1, \ldots, T$ :

$$
E_{\tau^{+}}\left(V_{\tau}^{*}\right)=I_{\tau}+P_{\tau}
$$

where

$$
V_{T}^{*}=I_{T}+P_{T}
$$

As mentioned above, the equity can be interpreted as a $t$-dimensional compound option. This is the case because the equity holders have the option either to pay the interest and principal repayment and buy a $(T-1)$-dimensional option or to forfeit the firm to the debtholders at each interest payment and repayment date (see also Geske (1979)).

Finally, the value of the risky debt of the firm can be derived using

$$
\begin{aligned}
D_{0} & =V_{0}-E_{0} \\
& =V_{0}\left[1-N_{T}\left(d_{1}^{1}, \ldots, d_{1}^{T} ; \rho_{T}\right)\right]+\sum_{t=1}^{T}\left(I_{t}+P_{t}\right) e^{-r \cdot t} \cdot N_{t}\left(d_{2}^{1}, \ldots, d_{2}^{t} ; \rho_{t}\right){ }^{6}
\end{aligned}
$$

The debtholders can be seen as holders of risk-free debt and writers of a put option on the total assets while the equity holders can be viewed as the holders of this specific put option. Bankruptcy is analogous to the execution of the option.

${ }^{6}$ See Fischer et al. (2000) 


\subsection{Repayment-Specific Formulas}

We present the formulas for valuing a firm's debt for four different types of principal repayment arrangements. First, take the case that the risky debt is present in the shape of a zero-coupon bond. No interest or principal payments occur during the term of the bond. The only payment occurs at maturity when the face value is paid to the debtholder. In this case, the value of the risky debt at $t=0$ can be calculated using the Merton (1974) formula

$$
\begin{aligned}
D_{0} & =V_{0}-E_{0} \\
& =V_{0} \cdot\left[1-N\left(d_{1}\right)\right]+N o m \cdot e^{-r \cdot T} \cdot N\left(d_{2}\right) .
\end{aligned}
$$

Second, the debt of the firm may be present in the shape of a coupon bond with lump sum repayment. This means that interest payments are due periodically according to the time interval specified in the bond indenture (e.g., annually, semi-annually) and that the face value of the debt has to be repaid at maturity. It follows that

$$
I=i_{\text {nom }} \cdot \mathrm{Nom}
$$

and the value of the risky debt can be calculated as

$$
\begin{aligned}
D_{0}= & V_{0}-E_{0} \\
= & V_{0}\left[1-N_{T}\left(d_{1}^{1}, \ldots, d_{1}^{T} ; \rho_{T}\right)\right]+\sum_{t=1}^{T} I_{t} \cdot e^{-r \cdot t} \cdot N_{t}\left(d_{2}^{1}, \ldots, d_{2}^{t} ; \rho_{t}\right)+ \\
& \quad N o m \cdot e^{-r \cdot T} \cdot N_{T}\left(d_{2}^{1}, \ldots, d_{2}^{T} ; \rho_{T}\right) .^{7}
\end{aligned}
$$

Third, the specifications of the firm's debt may state annuity repayment. This implies that a constant annuity, which is composed of both interest as well as principal repayment, is due at periodic payment dates. The annuity can be calculated using

$$
A n n=A F_{i_{\text {nom }, T}} \cdot \mathrm{Nom}
$$

where

$$
A F_{i_{\text {nom }, T}}=\frac{\left(1+i_{\text {nom }, T}\right)^{T} \cdot i_{\text {nom }, T}}{\left(1+i_{\text {nom }, T}\right)^{T}-1} .
$$

In this setting, the interest in each period depends on the outstanding nominal value at the beginning of the corresponding period

$$
I_{t}=i_{n o m} \cdot N_{o m}{ }_{t-1}
$$

where

$$
\operatorname{Nom}_{t}=\operatorname{Nom}_{t-1}-P_{t}
$$

${ }^{7}$ See Fischer et al. (2000) 
and

$$
\sum_{t=1}^{T} P_{t}=\text { Nom }_{0}
$$

The principal repayment at time $t$ is

$$
P_{t}=A n n-I_{t}=P_{1} *\left(1+i_{n o m}\right)^{(t-1)}
$$

and the value of the risky debt at $t=0$ is

$$
\begin{aligned}
D_{0} & =V_{0}-E_{0} \\
& =V_{0}\left[1-N_{T}\left(d_{1}^{1}, \ldots, d_{1}^{T} ; \rho_{T}\right)\right]+\sum_{t=1}^{T} A n n \cdot e^{-r \cdot t} \cdot N_{t}\left(d_{2}^{1}, \ldots, d_{2}^{t} ; \rho_{t}\right) .
\end{aligned}
$$

Fourth, the debt may specify constant principal repayments, $P$. In this case, the value of the risky debt is

$$
\begin{aligned}
D_{0} & =V_{0}-E_{0} \\
& =\left[1-N_{T}\left(d_{1}^{1}, \ldots, d_{1}^{T} ; \rho_{T}\right)\right]+\sum_{t=1}^{T}\left(I_{t}+P_{t}\right) \cdot e^{-r \cdot t} \cdot N_{t}\left(d_{2}^{1}, \ldots, d_{2}^{t} ; \rho_{t}\right){ }^{8}
\end{aligned}
$$

\subsection{Interpretation and Analysis}

For a more detailed interpretation of the components of the value of the risky debt at time $t=0$, the generic equation for any kind of repayment specification can be written as

$$
\begin{gathered}
D_{0}=\sum_{t=1}^{T}\left(I_{t}+P_{t}\right) \cdot e^{-r \cdot t} \\
-\sum_{t=1}^{T}\left[\left(I_{t}+P_{t}\right) \cdot e^{-r \cdot t}-V_{0} \cdot \frac{N_{t-1}\left(d_{1}^{1}, \ldots, d_{1}^{t-1} ; \rho_{t-1}\right)-N_{t}\left(d_{1}^{1}, \ldots, d_{1}^{t} ; \rho_{t}\right)}{N_{t-1}\left(d_{2}^{1}, \ldots, d_{2}^{t-1} ; \rho_{t-1}\right)-N_{t}\left(d_{2}^{1}, \ldots, d_{2}^{t} ; \rho_{t}\right)}\right] \cdot\left[N_{t-1}\left(d_{2}^{1}, \ldots, d_{2}^{t-1} ; \rho_{t-1}\right)-N_{t}\left(d_{2}^{1}, \ldots, d_{2}^{t} ; \rho_{t}\right)\right]
\end{gathered}
$$

where

$$
\operatorname{Prob}^{\prime}(\text { No Default until } t)=N_{t}\left(d_{2}^{1}, \ldots, d_{2}^{t} ; \rho_{t}\right)
$$

is the cumulative risk-neutral survival probability until time $t$ and conversely

$$
\operatorname{Prob}^{\prime}(\text { Default until } t)=1-N_{t}\left(d_{2}^{1}, \ldots, d_{2}^{t} ; \rho_{t}\right)
$$

represents the risk-neutral default probability until time $t$.

${ }^{8}$ See Fischer et al. (2000) 
From equation (12) it can be seen that the value of the risky debt can be interpreted as the value of a riskless bond (first term on the righthand side) less the present value of the expected losses for all periods (summation term). The latter is the sum over the product of two components - the discounted loss given default and the risk-neutral total probability of default - at each period $t$.

The total risk-neutral probability of default at time $t$ is calculated using

$$
\begin{aligned}
& \operatorname{Prob}^{\prime}(\text { No Default until } t-1 \text { and Default at } t) \\
& \qquad N_{t-1}\left(d_{2}^{1}, \ldots, d_{2}^{t-1} ; \rho_{t-1}\right)-N_{t}\left(d_{2}^{1}, \ldots, d_{2}^{t} ; \rho_{t}\right) \\
& \quad=N_{t-1}\left(d_{2}^{1}, \ldots, d_{2}^{t-1},-d_{2}^{t} ; \rho_{t}^{\prime}\right)
\end{aligned}
$$

where

$$
N_{0}:=1
$$

and

$$
\rho_{t}^{\prime}=\left\langle\rho_{\tau_{1}, \tau_{2}}^{\prime}\right\rangle= \begin{cases}1 & \text { if } \tau_{1}=\tau_{2}, \tau_{1}=1, \ldots, \tau, \tau_{2}=1, \ldots, \tau \\ \sqrt{\tau_{1} / \tau_{2}} & \text { if } \tau_{1}<\tau_{2}, \tau_{1}=1, \ldots, \tau, \tau_{2}=1, \ldots, \tau-1 \\ -\sqrt{\tau_{1} / \tau_{2}} & \text { if } \tau_{2}=\tau, \tau_{1}=1, \ldots, \tau \\ 0 & \text { else }\end{cases}
$$

Equation (12) can therefore be simplified to

$$
\begin{aligned}
D_{0} & =\sum_{t=1}^{T}\left(I_{t}+P_{t}\right) \cdot e^{-r \cdot t} \\
& -\sum_{t=1}^{T}\left[\left(I_{t}+P_{t}\right) \cdot e^{-r \cdot t}-V_{0} \cdot \frac{N_{t-1}\left(d_{1}^{1}, \ldots, d_{1}^{t-1},-d_{1}^{t} ; \rho_{t}^{\prime}\right)}{N_{t-1}\left(d_{2}^{1}, \ldots, d_{2}^{t-1},-d_{2}^{t} ; \rho_{t}^{\prime}\right)}\right] \cdot\left[N_{t-1}\left(d_{2}^{1}, \ldots, d_{2}^{t-1},-d_{2}^{t} ; \rho_{t}^{\prime}\right)\right]
\end{aligned}
$$

Besides the cumulative and the total risk-neutral default probabilities, also the conditional risk-neutral probability of default can be calculated

$$
\begin{aligned}
& \text { Prob }^{\prime}(\text { Default at } t \mid \text { No Default until } t-1) \\
& \qquad=\frac{\operatorname{Prob}^{\prime}(\text { Default until } t)-\operatorname{Prob}^{\prime}(\text { Default until } t-1)}{\operatorname{Prob}^{\prime}(\text { No Default until } t-1)} \\
& =\frac{N_{t-1}\left(d_{2}^{1}, \ldots, d_{2}^{t-1} ; \rho_{t-1}\right)-N_{t}\left(d_{2}^{1}, \ldots, d_{2}^{t} ; \rho_{t}\right)}{N_{t-1}\left(d_{2}^{1}, \ldots, d_{2}^{t-1} ; \rho_{t-1}\right)}
\end{aligned}
$$

Using these insights, the risk-neutral recovery rate equals

${ }^{9}$ For the proof see Fischer et al. (2000), Appendix A. 


$$
\begin{aligned}
R R_{t}^{\prime} & =\frac{V_{0} \cdot e^{r \cdot t}}{I_{t}+\operatorname{Nom}_{t-1}} \cdot \frac{N_{t-1}\left(d_{1}^{1}, \ldots, d_{1}^{t-1} ; \rho_{t-1}\right)-N_{t}\left(d_{1}^{1}, \ldots, d_{1}^{t} ; \rho_{t}\right)}{N_{t-1}\left(d_{2}^{1}, \ldots, d_{2}^{t-1} ; \rho_{t-1}\right)-N_{t}\left(d_{2}^{1}, \ldots, d_{2}^{t} ; \rho_{t}\right)} \\
& =\frac{V_{0} \cdot e^{r \cdot t}}{I_{t}+\operatorname{Nom}_{t-1}} \cdot \frac{N_{t-1}\left(d_{1}^{1}, \ldots, d_{1}^{t-1},-d_{1}^{t} ; \rho_{t}^{\prime}\right)}{N_{t-1}\left(d_{2}^{1}, \ldots, d_{2}^{t-1},-d_{2}^{t} ; \rho_{t}^{\prime}\right)}
\end{aligned}
$$

The continuous (expected) yield to maturity of debt for risk-neutral investors, $E_{0}^{\prime}\left(y_{T}\right)$, can be derived from

$$
D_{0}=\sum_{t=1}^{T} E_{0}{ }^{\prime}\left(\operatorname{Cash~Flow~}_{t}\right) \cdot e^{-E_{0^{\prime}}\left(y_{T}\right) \cdot t}
$$

using the expected risk-neutral cash flow for each period.

$$
\begin{aligned}
E_{0}^{\prime}\left(\text { Cash Flow }_{t}\right) & =\left(I_{t}+P_{t}\right) \cdot \text { Prob }^{\prime}(\text { No Default until } t) \\
& +E_{0}{ }^{\prime}\left(V_{t} \mid \text { No Default until } t-1 \text { and Default at } t\right)
\end{aligned}
$$

$$
\begin{aligned}
& E_{0}{ }^{\prime}\left(V_{t} \mid \text { No Default until } t-1 \text { and Default at } t\right) \\
& \qquad \begin{aligned}
\\
\end{aligned} \\
& \quad=V_{0} \cdot e^{r \cdot t} \cdot\left[N_{t-1}\left(d_{1}^{1}, \ldots, d_{1}^{t-1} ; \rho_{t-1}\right)-N_{t}\left(d_{1}^{1}, \ldots, d_{1}^{t} ; \rho_{t}\right)\right] .
\end{aligned}
$$

Consequently, the value of the debt at $t=0$ is

$$
\begin{aligned}
D_{0}= & \sum_{t=1}^{T}\left\{V_{0} \cdot e^{r \cdot t} \cdot\left[N_{t-1}\left(d_{1}^{1}, \ldots, d_{1}^{t-1} ; \rho_{t-1}\right)-N_{t}\left(d_{1}^{1}, \ldots, d_{1}^{t} ; \rho_{t}\right)\right]\right. \\
& \left.+\left(I_{t}+P_{t}\right) \cdot N_{t}\left(d_{2}^{1}, \ldots, d_{2}^{t} ; \rho_{t}\right)\right\} \cdot e^{-E_{0}^{\prime}\left(y_{T}\right) \cdot t} .
\end{aligned}
$$

\subsection{Risk Aversion}

It has been shown that in reality the assumption of risk-neutrality, which is often made in theoretical models, rarely holds. Typical investors are risk-averse and not willing to invest at the risk-free interest rate. Instead, they require compensation for bearing risk and are therefore more interested in the risk-adjusted yield rather than the risk-neutral yield. We therefore additionally outline the calculation of the risk-averse probabilities as well as the risk-adjusted yield to cater to this preference.

In the risk-neutral setting, the risk-free interest rate $r$ is used to calculate the riskneutral yield based on the promised interest and principal payments. In the risk-averse setting, $r$ can no longer be used. Instead the instantaneous drift of the total assets, $\mu_{V}$, must be calculated in order to determine the risk-adjusted yield based on the riskaverse expected interest and principal payments. This is done based on the intertemporal CAPM by Merton (1973)

$$
\mu_{V}=r+\left(\mu_{M}-r\right) \cdot \beta_{V}
$$

where $\mu_{M}$ is the drift of the market of unlevered assets and $\beta_{V}$ is the beta factor of the firm's assets. The market drift is given exogenously, whereas the asset beta factor can either be exogenously given or determined iteratively from 
where

$$
\beta_{E}=\Delta_{E} \cdot \frac{V_{0}}{E_{0}} \cdot \beta_{V}
$$

$$
\Delta_{E}=N_{T}\left(d_{1}^{1}, \ldots, d_{1}^{T} ; \rho_{T}\right)
$$

if the equity beta $\beta_{E}$ is estimated empirically. $\mu_{V}$ is then used to calculate the riskaverse survival probability until time $t$

$$
\operatorname{Prob}(\text { No Default until } t)=N_{t}\left(k_{2}^{1}, \ldots, k_{2}^{t} ; \rho_{t}\right)
$$

where

$$
k_{1}^{\tau}=\frac{\ln \left(\frac{V_{0}}{V_{\tau}^{*}}\right)+\left(\mu_{V}+\frac{\sigma_{V}^{2}}{2}\right) \cdot \tau}{\sigma_{V} \cdot \sqrt{\tau}}
$$

and

$$
k_{2}^{\tau}=k_{1}^{\tau}-\sigma_{V} \cdot \sqrt{\tau}
$$

Conversely the risk-averse cumulative default probability until time $t$ is

$$
\operatorname{Prob}(\text { Default until } t)=1-N_{t}\left(k_{2}^{1}, \ldots, k_{2}^{t} ; \rho_{t}\right) \text {. }
$$

The risk-averse total default probability at time $t$ is

$$
\begin{aligned}
& \operatorname{Prob}(\text { No Default until } t-1 \text { and Default at } t) \\
& \qquad=N_{t-1}\left(k_{2}^{1}, \ldots, k_{2}^{t-1} ; \rho_{t-1}\right)-N_{t}\left(k_{2}^{1}, \ldots, k_{2}^{t} ; \rho_{t}\right) \\
& \quad=N_{t-1}\left(k_{2}^{1}, \ldots, k_{2}^{t-1},-k_{2}^{t} ; \rho_{t}^{\prime}\right) .
\end{aligned}
$$

Finally, the conditional risk-averse probability of default at time $t$ is

$$
\begin{aligned}
& \operatorname{Prob}(\text { Default at } t \mid N o \text { Default until } t-1) \\
& \qquad=\frac{\operatorname{Prob}(\text { Default until } t)-\operatorname{Prob}(\text { Default until } t-1)}{\operatorname{Prob}(N o \text { Default until } t-1)} \\
& =\frac{N_{t-1}\left(k_{2}^{1}, \ldots, k_{2}^{t-1} ; \rho_{t-1}\right)-N_{t}\left(k_{2}^{1}, \ldots, k_{2}^{t} ; \rho_{t}\right)}{N_{t-1}\left(k_{2}^{1}, \ldots, k_{2}^{t-1} ; \rho_{t-1}\right)} .
\end{aligned}
$$

The risk-averse recovery rate is

$$
R R_{t}=\frac{V_{0} \cdot e^{\mu_{V} \cdot t}}{I_{t}+N_{t-1}} \cdot \frac{N_{t-1}\left(k_{1}^{1}, \ldots, k_{1}^{t-1} ; \rho_{t-1}\right)-N_{t}\left(k_{1}^{1}, \ldots, k_{1}^{t} ; \rho_{t}\right)}{N_{t-1}\left(k_{2}^{1}, \ldots, k_{2}^{t-1} ; \rho_{t-1}\right)-N_{t}\left(k_{2}^{1}, \ldots, k_{2}^{t} ; \rho_{t}\right)}
$$

The continuous (expected) yield to maturity of debt for risk-averse investors, $E_{0}\left(y_{T}\right)$, is derived from 


$$
D_{0}=\sum_{t=1}^{T} E_{0}\left(\operatorname{Cash~Flow~}_{t}\right) \cdot e^{-E_{0}\left(y_{T}\right) \cdot t}
$$

where the expected cash flows at each payment date are

$$
\begin{aligned}
E_{0}\left(\text { Cash Flow }_{t}\right) & =\left(I_{t}+P_{t}\right) \cdot N_{t}\left(k_{2}^{1}, \ldots, k_{2}^{t} ; \rho_{t}\right) \\
& +V_{0} \cdot e^{\mu_{V} \cdot t} \cdot\left[N_{t-1}\left(k_{2}^{1}, \ldots, k_{2}^{t-1} ; \rho_{t-1}\right)-N_{t}\left(k_{2}^{1}, \ldots, k_{2}^{t} ; \rho_{t}\right)\right] .
\end{aligned}
$$

It follows that the market value of debt at $t=0$ is

$$
\begin{gathered}
D_{0}=\sum_{t=1}^{T}\left\{V_{0} \cdot e^{\mu_{V} \cdot t} \cdot\left[N_{t-1}\left(k_{1}^{1}, \ldots, k_{1}^{t-1} ; \rho_{t-1}\right)-N_{t}\left(k_{1}^{1}, \ldots, k_{1}^{t} ; \rho_{t}\right)\right]\right. \\
\left.+\left(I_{t}+P_{t}\right) \cdot N_{t}\left(k_{2}^{1}, \ldots, k_{2}^{t} ; \rho_{t}\right)\right\} \cdot e^{-E_{0}\left(y_{T}\right) \cdot t}
\end{gathered}
$$

It is then possible to calculate the instantaneous volatility of debt, $\sigma_{D}$, and equity, $\sigma_{E}$,

$$
\begin{aligned}
& \sigma_{D}=\Delta_{D} \cdot \frac{V_{0}}{D_{0}} \cdot \sigma_{V} \\
& \sigma_{E}=\Delta_{E} \cdot \frac{V_{0}}{E_{0}} \cdot \sigma_{V}
\end{aligned}
$$

where

$$
\Delta_{D}=\left[1-N_{T}\left(d_{1}^{1}, \ldots, d_{1}^{T} ; \rho_{T}\right)\right]
$$

and

$$
\Delta_{E}=N_{T}\left(d_{1}^{1}, \ldots, d_{1}^{T} ; \rho_{T}\right)
$$

as well as the debt and equity betas

$$
\begin{aligned}
& \beta_{D}=\Delta_{D} \cdot \frac{V_{0}}{D_{0}} \cdot \beta_{V} \\
& \beta_{E}=\Delta_{E} \cdot \frac{V_{0}}{E_{0}} \cdot \beta_{V} .
\end{aligned}
$$

Furthermore, it may be of interest to calculate the distance to default. The distance to default shows how many standard deviations of the return of the asset lie between the value of the asset and its bankruptcy point (i.e., the killing price $V_{t}^{*}$ ).

$$
N_{T}\left(D D_{1}{ }^{\prime}, \ldots, D D_{T}{ }^{\prime} ; \rho_{T}\right)=N_{T}\left(d_{2}^{1}, \ldots, d_{2}^{T} ; \rho_{T}\right)
$$

Since

$$
\operatorname{Prob}^{\prime}(\text { Survive until } t)=N_{t}\left(d_{2}^{1}, \ldots, d_{2}^{t} ; \rho_{t}\right) \text {, }
$$

for risk-neutral investors the distance to default for each period $t, D D_{t}^{\prime}$, is 


$$
D D_{t}^{\prime}=\frac{\ln \frac{V_{0}}{V_{t}^{*}}+\left(r-\frac{\sigma_{V}^{2}}{2}\right) t}{\sigma_{V} \sqrt{t}} .
$$

For risk-averse investors the derivation applies analogously.

$$
N_{T}\left(D D_{1}, \ldots, D D_{T} ; \rho_{T}\right)=N_{T}\left(k_{2}^{1}, \ldots, k_{2}^{T} ; \rho_{T}\right)
$$

Again, since

$$
\operatorname{Prob}(\text { Survive until } t)=N_{t}\left(k_{2}^{1}, \ldots, k_{2}^{t} ; \rho_{t}\right)
$$

the risk-adjusted distance to default for each period $t, D D_{t}$, is

$$
D D_{t}=\frac{\ln \frac{V_{0}}{V_{t}^{*}}+\left(\mu_{V}-\frac{\sigma_{V}^{2}}{2}\right) t}{\sigma_{V} \sqrt{t}} .
$$

\subsection{Numerical Example}

We present a numerical example to illustrate our formulas for the coherent valuation of the debt. We value the debt of a firm whose total assets consist of non-dividend paying equity and a single debt instrument, namely a loan with lump sum repayment. The basic parameters are shown in Table 1. The value of the total assets of the firm amounts to 100 , the volatility of the assets is $15 \%$, and the beta of the firm's assets is 1. The nominal value of the debt instrument is 70 and the maturity of the debt is five years. Furthermore, the risk-free rate of interest is $2 \%$ p.a. and the drift of the market of unlevered assets is $4 \%$ p.a.

\begin{tabular}{|l|r|}
\hline Term T & 5 \\
\hline Asset value $V_{0}$ & 100.00 \\
\hline Face value Nom $_{0}$ & 70.00 \\
\hline Risk-free rate $r$ & $2.00 \%$ \\
\hline Asset volatility $\sigma_{V}$ & $15.00 \%$ \\
\hline Asset beta $\beta_{V}$ & 1.00 \\
\hline $\begin{array}{l}\text { Drift of the market of } \\
\text { unlevered assets } \mu_{M}\end{array}$ & $4.00 \%$ \\
\hline
\end{tabular}
Table 1: Parameters of a Single Debt Instruments

As can be seen from Table 2, the firm pays annual interest at a nominal interest rate of $2.5 \%$ on its loan. This corresponds to a risk premium of $50 \mathrm{bp}$ over the risk-free rate of interest. The value of the risk-free debt at $t=0$, which is the present value of the promised payments discounted with the risk-free interest rate, amount to 70.58 . This corresponds to the first term on the righthand side of equation (12). The value of the risky debt at $t=0$ is 70.24 . As mentioned in Section 2.4, this corresponds to the value of the risk-free debt less the present value of the expected losses for all future periods. 


\begin{tabular}{|c|c|c|c|c|c|c|}
\hline Time $\mathbf{t}$ & 0 & 1 & 2 & 3 & 4 & 5 \\
\hline Risk premium RP & $50 \mathrm{bp}$ & & & & & \\
\hline Nominal interest rate p.a. $\mathrm{i}_{\text {nom }}$ & $2.50 \%$ & & & & & \\
\hline Value of risk-free debt $D_{0}^{\text {riskless }}$ & 70.58 & & & & & \\
\hline Value of risky debt $D_{0}^{\text {risky }}$ & 70.24 & & & & & \\
\hline Killing prices $V_{t}^{*}$ & & 60.08 & 60.91 & 62.18 & 64.45 & 71.75 \\
\hline Cumulative $\mathrm{PD}_{\mathrm{t}}^{\prime}$ & & $0.03 \%$ & $0.79 \%$ & $2.95 \%$ & $6.51 \%$ & $14.17 \%$ \\
\hline Cumulative $\mathrm{PD}_{\mathrm{t}}$ & & $0.02 \%$ & $0.46 \%$ & $1.70 \%$ & $3.80 \%$ & $8.56 \%$ \\
\hline Total $\mathrm{PD}_{\mathrm{t}}^{\prime}$ & & $0.03 \%$ & $0.76 \%$ & $2.16 \%$ & $3.56 \%$ & $7.66 \%$ \\
\hline Total $\mathrm{PD}_{\mathrm{t}}$ & & $0.02 \%$ & $0.45 \%$ & $1.24 \%$ & $2.10 \%$ & $4.75 \%$ \\
\hline Conditional $\mathrm{PD}_{\mathrm{t}}^{\prime}$ & & $0.03 \%$ & $0.76 \%$ & $2.18 \%$ & $3.67 \%$ & $8.19 \%$ \\
\hline Conditional $\mathrm{PD}_{\mathrm{t}}$ & & $0.02 \%$ & $0.45 \%$ & $1.25 \%$ & $2.13 \%$ & $4.94 \%$ \\
\hline Recovery rate $\mathrm{RR}_{\mathrm{t}}^{\prime}$ & & $80.65 \%$ & $79.42 \%$ & $78.14 \%$ & $83.58 \%$ & $89.57 \%$ \\
\hline Recovery rate $R_{t}$ & & $80.74 \%$ & $79.67 \%$ & $80.27 \%$ & $81.90 \%$ & $91.71 \%$ \\
\hline $\mathrm{E}_{0}^{\prime}\left(\right.$ Cash Flow $\left._{\mathrm{t}}\right)$ & & 1.77 & 2.17 & 2.91 & 3.77 & 66.51 \\
\hline $\mathrm{E}_{0}\left(\right.$ Cash Flow $\left.{ }_{\mathrm{t}}\right)$ & & 1.76 & 2.00 & 2.43 & 2.92 & 68.74 \\
\hline Distance to default $\mathrm{DD}_{\mathrm{t}}^{\prime}$ & & 3.46 & 2.42 & 1.93 & 1.58 & 1.12 \\
\hline Distance to default $\mathrm{DD}_{\mathrm{t}}$ & & 3.59 & 2.61 & 2.16 & 1.85 & 1.42 \\
\hline
\end{tabular}

Table 2 also gives an overview of the killing prices for each period which are monotonically increasing. While the cumulative probabilities of the default (PD) increase over time by definition, it can be seen that also the total as well as the conditional probabilities increase over time. Both the risk-neutral as well as the riskaverse default probabilities increase more strongly with longer maturity. The riskadverse probabilities are uniformly lower than their risk-neutral counterparts. The recovery rates $(R R)$ also increase towards maturity. However, the risk-adjusted recovery rates exceed the risk-neutral rates in all periods. Table 2 also shows the expected cash flows in comparison with the expected risk-neutral cash flows for each period. The risk-neutral cash flows exceed their risk-adjusted counterparts in all periods except $t=5$ when the repayment is expected to take place. The distance to default (DD) for the lump sum loan decreases with time which the risk-averse distance exceeding the risk-neutral values.

Next, we compare the valuation results for the lump sum loan with three other scenarios. We again value the same firm as mentioned above using the parameters specified in Table 1. For each valuation, we replace the firm's debt with a different debt instrument. The nominal value of the debt in each scenario remains 70 , merely the interest payment structure and the repayment modalities change. The results are summarized in Table 3. The first numerical column shows the results for the firm with the lump sum loan which we valued at the beginning of this section. Columns 2 shows the results when the loan is equipped with annuity repayment instead. Column 3 depicts the case where constant principal repayments are specified for the debt instruments. Finally, column 4 shows the results when the debt instrument is present in the shape of a zero bond that is redeemed at its nominal value at maturity. As can be seen from Table 3, in the first three scenarios the debt pays annual interest of $2.5 \%$. The zero-bond naturally does not pay any periodical interest. 


\begin{tabular}{|c|c|c|c|c|}
\hline Form of Repayment & $\begin{array}{l}\text { Lump } \\
\text { Sum }\end{array}$ & Annuity & $\begin{array}{l}\text { Constant } \\
\text { Principal }\end{array}$ & $\begin{array}{c}\text { Zero } \\
\text { Coupon }\end{array}$ \\
\hline Nominal interest rate p.a. $\mathrm{i}_{\text {nom }}$ & $2.50 \%$ & $2.50 \%$ & $2.50 \%$ & - \\
\hline Value of risk-free debt $\mathrm{D}_{0}^{\text {riskless }}$ & 71.58 & 70.98 & 70.96 & 63.34 \\
\hline Value of risky debt $D_{0}^{\text {risky }}$ & 70.24 & 70.92 & 70.91 & 62.29 \\
\hline Instantaneous debt volatility $\sigma_{\mathrm{D}}$ & $1.71 \%$ & $0.21 \%$ & $0.21 \%$ & $1.68 \%$ \\
\hline Instantaneous equity volatility $\sigma_{\mathrm{E}}$ & $46.36 \%$ & $51.07 \%$ & $51.06 \%$ & $37.00 \%$ \\
\hline Debt beta $\beta_{\mathrm{D}}$ & 0.11 & 0.01 & 0.01 & 0.11 \\
\hline Equity beta $\beta_{\mathrm{E}}$ & 3.09 & 3.40 & 3.40 & 2.47 \\
\hline Debt drift $\mu_{D}$ & $2.23 \%$ & $2.03 \%$ & $2.03 \%$ & $2.22 \%$ \\
\hline Equity drift $\mu_{\mathrm{E}}$ & $8.18 \%$ & $8.81 \%$ & $8.81 \%$ & $6.93 \%$ \\
\hline Promised continuous yield to maturity $\mathrm{y}_{\mathrm{T}}$ & $2.40 \%$ & $1.87 \%$ & $2.03 \%$ & $2.33 \%$ \\
\hline $\begin{array}{l}\text { Expected risk-neutral continuous yield to } \\
\text { maturity } \mathrm{E}_{0}^{\prime}\left(\mathrm{y}_{\mathrm{T}}\right)\end{array}$ & $2.00 \%$ & $2.00 \%$ & $2.00 \%$ & $2.00 \%$ \\
\hline $\begin{array}{l}\text { Expected risk-averse continuous yield to } \\
\text { maturity } \mathrm{E}_{0}\left(\mathrm{y}_{\mathrm{T}}\right)\end{array}$ & $2.17 \%$ & $2.01 \%$ & $2.01 \%$ & $2.17 \%$ \\
\hline
\end{tabular}

As above, the value of the risk-free and risky debt instrument is calculated for each scenario. For the lump sum loan, the annuity loan, and the loan with constant principal repayments this is done using the formulas presented in Section 2.3. The present value of the zero-coupon debt is derived using the Merton formula (equation (1)).

The results show that the instantaneous volatility of debt is much higher for the lump sum repayment and the zero bond because the repayment of both debt instruments occurs late in the debt instruments' lifetime. The promised continuous yield to maturity is the maximum yield that can be achieved via these debt instruments. Naturally, the expected continuous yields to maturity lie below the promised yields and the expected risk-neutral yield corresponds to the risk-free interest rate for each debt instrument. The expected risk-averse continuous yields to maturity lie below the promised but above the expected risk-neutral yields. They are highest for the lump sum and zerocoupon scenarios.

\section{Multiple Debt Instruments}

In many cases, a firm's debt will consist not only of a single debt instrument but of multiple debt instruments. When a firm's debt consists of a portfolio of different instruments, the valuation of each specific debt instrument needs to be modified since the recovery rates in the event of bankruptcy change at each point in time. The valuation of the equity and the determination of the trigger values for bankruptcy, $V_{t}^{*}$, do not change and can be carried out as described in the previous section.

\subsection{Valuation Setup}

In our second extension of the basic model we assume the firm has multiple debt instruments in addition to equity. We again base our formulas on a few simple assumptions. First, it is assumed that all debt securities will mature at time $T$ and that they are all of the same rank. Furthermore, the nominal value of the entire debt at time $t, N_{t}$, is the sum of the specific debt instrument under consideration, $\operatorname{Nom}_{t}^{S}$, and the remaining miscellaneous debt instruments, $\operatorname{Nom}_{t}^{M}$. 


$$
\operatorname{Nom}_{t}=\operatorname{Nom}_{t}^{S}+\operatorname{Nom}_{t}^{M}
$$

The total interest and principal payments are in turn the sum of the respective specific and miscellaneous parts.

$$
\begin{gathered}
I_{t}=I_{t}^{S}+I_{t}^{M} \\
P_{t}=P_{t}^{S}+P_{t}^{M}
\end{gathered}
$$

In consequence, the claims of the creditors of the specific debt capital to be valued at time $t$ are

$$
\gamma_{t}=\frac{\operatorname{Nom}_{t-1}^{S}+I_{t}^{S}}{\operatorname{Nom}_{t-1}+I_{t}}
$$

\subsection{Valuation}

The value of a specific debt instrument at maturity is

$$
D_{T}^{S}=\left\{\begin{array}{ll}
\gamma_{T} \cdot V_{T} & \text { if } V_{T}<\operatorname{Nom}_{T-1}^{S}+I_{T}^{S} \\
\operatorname{Nom}_{T-1}^{S}+I_{T}^{S} & \text { if } V_{T} \geq \operatorname{Nom}_{T-1}^{S}+I_{T}^{S}
\end{array}\right\} .
$$

At time $(T-1)^{-}$, momentarily before the final interest and principal payments, the value of the debt can be expressed as

$$
\begin{aligned}
D_{(T-1)^{-}}^{S} & =\left\{\begin{array}{ll}
\gamma_{T-1} \cdot V_{T-1} & \text { falls } V_{T-1}<V_{T-1}^{*} \\
0 & \text { falls } V_{T-1} \geq V_{T-1}^{*}
\end{array}\right\} \\
& +\left\{\begin{array}{ll}
0 & \text { if } V_{T-1}<V_{T-1}^{*} \\
\gamma_{T} \cdot V_{T-1} & \text { if } V_{T-1} \geq V_{T-1}^{*}
\end{array}\right\} \\
& -\left\{\begin{array}{ll}
0 & \text { if } V_{T-1}<V_{T-1}^{*} \\
\gamma_{T} \cdot E_{(T-1)^{+}}-\left(P_{T-1}^{S}+I_{T-1}^{S}\right) & \text { if } V_{T-1} \geq V_{T-1}^{*}
\end{array}\right\} .
\end{aligned}
$$

The first term and the middle term on the righthand side of equation (34) can be seen as a short put and a long call, respectively, on $\gamma_{T-1}$ parts of the total assets against a payment of zero. The third term is a short call on $\gamma_{T}$ parts of the equity against a payment of $P_{T-1}^{S}+I_{T-1}^{S}$. This short call is virtually a compound option since the equity itself represents an option on the total assets.

One period earlier still, at time $(T-2)^{+}$, momentarily after the interest and principal payments, the value of the debt is

$$
\begin{aligned}
D_{(T-2)^{+}}^{S}=V_{T-2} \cdot\left[\gamma_{T-1}+\left(\gamma_{T}-\gamma_{T-1}\right) \cdot N\left(h_{1}^{1}\right)-\gamma_{T} \cdot N_{2}\left(h_{1}^{1}, h_{1}^{2} ; \rho_{2}\right)\right] \\
+\left(I_{T-1}^{S}+P_{T-1}^{S}\right) \cdot e^{-r} \cdot N\left(h_{2}^{1}\right)+\left(I_{T}^{S}+P_{T}^{S}\right) \cdot e^{-2 \cdot r} \cdot N_{2}\left(h_{2}^{1}, h_{2}^{2} ; \rho_{2}\right)
\end{aligned}
$$

with

$$
\begin{aligned}
h_{1}^{1} & =\frac{\ln \left(\frac{V_{T-2}}{V_{T-1}^{*}}\right)+r+\frac{\sigma_{V}^{2}}{2}}{\sigma_{V}} \\
h_{2}^{1} & =h_{1}^{1}-\sigma_{V}
\end{aligned}
$$


and

$$
\begin{aligned}
h_{1}^{2}= & \frac{\ln \left(\frac{V_{T-2}}{I_{T}^{S}+P_{T}^{S}}\right)+\left(r+\frac{\sigma_{V}^{2}}{2}\right) \cdot 2}{\sigma_{V} \cdot \sqrt{2}} \\
h_{2}^{2}= & h_{1}^{2}-\sigma_{V} \cdot \sqrt{2} .
\end{aligned}
$$

Analogous to the value of the equity, the market value of the specific debt instrument at $t=0$ is obtained using

$$
\begin{aligned}
D_{0}^{S} & =V_{0}\left[\gamma_{1}+\sum_{t=1}^{T-1}\left(\gamma_{t+1}-\gamma_{t}\right) \cdot N_{t}\left(d_{1}^{1}, \ldots, d_{1}^{t} ; \rho_{t}\right)-\gamma_{T} \cdot N_{T}\left(d_{1}^{1}, \ldots, d_{1}^{T} ; \rho_{T}\right)\right] \\
& +\sum_{t=1}^{T}\left(I_{t}^{S}+P_{t}^{S}\right) e^{-r \cdot t} \cdot N_{t}\left(d_{2}^{1}, \ldots, d_{2}^{t} ; \rho_{t}\right) .
\end{aligned}
$$

In the special case that $\gamma_{t}$ is constant, the market value of the specific debt instrument is

$$
\begin{aligned}
D_{0}^{S} & =\gamma \cdot V_{0}\left[1-N_{T}\left(d_{1}^{1}, \ldots, d_{1}^{T} ; \rho_{T}\right)\right] \\
& +\sum_{t=1}^{T}\left(I_{t}^{S}+P_{t}^{S}\right) e^{-r \cdot t} \cdot N_{t}\left(d_{2}^{1}, \ldots, d_{2}^{t} ; \rho_{t}\right) .
\end{aligned}
$$

\subsection{Default Clause Regulations}

Bondholders may call their bonds prematurely if the firm fails to service interest or principal payments on time. When a firm has multiple debt instruments outstanding, bondholders may even call their bonds prematurely if the firm fails to pay interest or principal repayments on time on any of the other debt instruments issued. This is regulated under the international default clause, which grants creditors the right to demand the immediate repayment of their bond or loan amount outstanding as soon as the debtor shows certain signs of a potential default (e.g., insolvency).

Similar regulations can be found under Anglo-American law in the so-called cross default clause. This is a clause in loan agreements and bond indentures according to which the default of a debtor in another credit relationship entitles the creditor to demand the early termination of his own obligation towards that debtor without there being any direct reason for termination. This is often referred to as acceleration.

\subsection{Practical Implementation}

In practical implementations the data for the valuation of the different debt instruments is obtained from a range of sources. For example, data is drawn from the plan balance sheets and the plan profit and loss statements as well as the firm's interest and redemption schedule. Data from the firm's strategic investment plan and its financial plan is also used in order to ensure that planned future borrowings can be taken into account. In addition to the firm-specific information the forecasts of the future interest rate levels play an important role. 
The procedure for practically implementing the calculations presented above is straightforward. When the present value of the assets, $V_{0}$, and the volatility of the assets, $\sigma_{V}$, are known, first, the interest and redemption schedules for all debt instruments are drawn up. From these schedules the claims of each creditor of the debt instrument to be priced at time $t, \gamma_{t}$, can be calculated. Using the reverse bootstrapping procedure mentioned in section 2.2, the equity capital is priced recursively from $T-1, T-2, \ldots, 1,0$ and the killing prices $V_{t}^{*}$ for each case are determined. Finally, each specific debt instrument can be valued at $t=0$ using the formulas presented above.

The more realistic situation is that $V_{0}$ and $\sigma_{V}$ are unknown. In this case $V_{0}$ and $\sigma_{V}$ must be calibrated from the present value of the equity, $E_{0}$, and its corresponding volatility, $\sigma_{E}$, which are known for listed firms. Again, in the first step, the interest and redemption schedules for all debt instruments must be drawn up. Next the reverse bootstrapping procedure is carried out to recursively value the equity capital from $T-1, T-$ $2, \ldots, 1,0$ and to determine the killing prices $V_{t}^{*}$ for each period. ${ }^{10}$

$$
\sigma_{E}=\Delta_{E} \cdot \frac{V_{0}}{S_{0} \cdot M} \cdot \sigma_{V}
$$

where

$$
\Delta_{E}=N_{T}\left(d_{1}^{1}, \ldots, d_{1}^{T} ; \rho_{T}\right) .
$$

This simultaneously leads to $V_{t}^{*}, V_{0}$, and $\sigma_{V}$. Finally, each specific debt instrument and the total debt capital can be valued at $t=0$ using the formulas presented above.

\subsection{Numerical Example}

We again present a numerical example to illustrate our formulas for the valuation of specific debt instruments out of a firm's debt portfolio. We build on the example presented in the previous section. Recall that we analyzed one firm with one single debt instrument in different interest and repayment modality scenarios (i.e., lump sum, annuity, constant principal, zero coupon). Here, we value one single firm but make the assumption that the firm's assets consist of two independent debt instruments in addition to its non-dividend paying equity. To be precise, the debt portfolio of the firm under consideration consists of a lump sum loan and a zero-coupon bond. The parameters from Table 1 are still valid, merely the total asset value is now changed to 200 as can be seen from Table 4. Each debt instrument has a nominal value of 70 . This ensures that the debt-to-assets ratio is identical to that of the previous example. The lump sum loan again pays annual interest of $2.5 \%$ while the zero-coupon debt pays no interest but is redeemed at par at maturity.

10 This approach was first employed within Moody's KMV model, a structural default prediction model frequently used in practice. For a detailed description of the derivation see Saunders and Allen (2010). 


\begin{tabular}{|l|r|r|}
\hline Form of Repayment Specific Debt & Lump Sum & Zero Coupon \\
\hline Asset Value $V_{0}$ & 200.00 \\
\hline Face value specific debt $\mathrm{Nom}_{0}^{\mathrm{S}}$ & 70.00 & 70.00 \\
\hline Nominal interest rate p.a. $\mathrm{i}_{\text {nom }}$ & $2.50 \%$ & - \\
\hline Share on total debt $\gamma_{\mathrm{t}}=\gamma$ & $50.62 \%$ & $49.38 \%$ \\
\hline Value of riskless debt $\mathrm{D}_{0}^{\text {riskless }}$ & 70.58 & 63.34 \\
\hline Value of risky debt $\mathrm{D}_{0}^{\text {risky }}$ & 70.35 & 62.23 \\
\hline Instantaneous debt volatility $\sigma_{\mathrm{D}}$ & $2.98 \%$ & $3.37 \%$ \\
\hline Instantaneous equity volatility $\sigma_{\mathrm{E}}$ & $41.39 \%$ & $41.39 \%$ \\
\hline Debt beta $\beta_{\mathrm{D}}$ & 0.20 & 0.22 \\
\hline Equity beta $\beta_{\mathrm{E}}$ & 2.76 & 2.76 \\
\hline Debt drift $\mu_{\mathrm{D}}$ & $2.40 \%$ & $2.45 \%$ \\
\hline Equity drift $\mu_{\mathrm{E}}$ & $7.52 \%$ & $7.52 \%$ \\
\hline Promised continuous yield to maturity $\mathrm{y}_{\mathrm{T}}$ & $2.37 \%$ & $2.35 \%$ \\
\hline $\begin{array}{l}\text { Expected risk-neutral continuous yield to } \\
\text { maturity } \mathrm{E}_{0}^{\prime}\left(\mathrm{y}_{\mathrm{T}}\right)\end{array}$ & $2.00 \%$ & $2.00 \%$ \\
\hline $\begin{array}{l}\text { Expected risk-averse continuous yield to } \\
\text { maturity } \mathrm{E}_{0}\left(\mathrm{y}_{\mathrm{T}}\right)\end{array}$ & $2.17 \%$ & $2.16 \%$ \\
\hline \multicolumn{2}{|c|}{ Table 4: Valuation Results for Firm with Two Debt Instrument (Lump Sum \& Zero-Coupon) }
\end{tabular}

We use our formulas to value each specific debt instrument. The results are also given in Table 4. The main insight from the valuation can be taken from the second numerical column which contains the results for the zero-coupon bond. Take the value of the riskless debt and the value of the risky debt, which are 63.32 and 62.23 , respectively. Recall the valuation results for the zero-coupon debt in the single debt instrument case in Section 2.6. Same is here in the multiple debt instrument scenario, the value of the riskless debt was 63.34. The value of the risky debt, however, was 62.29 in the single debt scenario. This clearly demonstrates that the Merton formula can no longer be used to value zero-coupon debt in situations where a firm's debt consists of a portfolio of different debt instruments. This is due to the fact that, as mentioned in Section 3.3, the default of one instrument in a debt portfolio has a direct impact on the other debt instruments in the portfolio and thus diminishes the value of the other instruments. This interdependency is also reflected in the expected risk-averse continuous yield to maturity which is 2.16 for the zero-coupon debt in the multi-debt scenario and $2.17 \%$ in the single-debt scenario.

Table 4 also shows that the structure of the debt is irrelevant for the valuation of the equity. The instantaneous equity volatility, the equity beta as well as the equity drift are identical for both the lump sum and the zero-coupon debt.

\section{Multiple Debt Instruments with Continuous Dividends}

The previous sections were based on the assumption that the firm pays no dividends to its equity holders. In our third and final extension of the basic Merton model we extend the previous considerations to incorporate continuous dividends. These dividends have a constant return of $q$. They reduce the value of the firm and are thus accounted for in the stochastic process of the firm's value via

$$
\frac{d V_{t}}{V_{t}}=\left(\mu_{V}-q\right) d t+\sigma_{V} d z
$$


The equity holders receive continuous dividend payments of $q \cdot V_{t}$ from $t=0$ until bankruptcy or $t=T$, whichever comes first.

\subsection{Valuation}

As shown by Galai and Wiener (2015), the present value of the expected continuous dividends under the classical Merton model is

$$
\begin{gathered}
V D_{0}=\int_{0}^{T} E_{0}^{\prime}\left(D_{i v_{t}}\right) e^{-r t} d t=\int_{0}^{T} q \cdot E_{0}^{\prime}\left(V_{\tau}\right) e^{-r t} d t=\int_{0}^{T} q \cdot V_{0} \cdot e^{(r-q) \cdot t} \cdot e^{-r t} d t \\
=\int_{0}^{T} q \cdot V_{0} \cdot e^{-q \cdot t} d t=V_{0} \cdot\left(1-e^{-q \cdot T}\right)
\end{gathered}
$$

and the ex-dividend value of the total assets is

$$
V_{0}^{e x}=V_{0}-V D_{0}=V_{0}-V_{0} \cdot\left(1-e^{-q \cdot T}\right)=V_{0} \cdot e^{-q \cdot T} .
$$

When the firm's debt is present in the shape of a zero bond, the value of the risky debt is calculated as

$$
D_{0}=V_{0}^{e x} \cdot\left[1-N\left(d_{1}^{e x}\right)\right]+N o m \cdot e^{-r \cdot T} \cdot N\left(d_{2}^{e x}\right)
$$

where

$$
d_{1}^{e x}=\frac{\ln \frac{V_{0}}{N o m}+\left(r-q+\frac{\sigma_{V}^{2}}{2}\right) T}{\sigma_{V} \cdot \sqrt{T}}
$$

and

$$
d_{2}^{e x}=\frac{\ln \frac{V_{0}}{N o m}+\left(r-q-\frac{\sigma_{V}^{2}}{2}\right) T}{\sigma_{V} \cdot \sqrt{T}}=d_{1}^{e x}-\sigma_{V} \cdot \sqrt{T} \text {. }
$$

The value of the equity can again be derived as a residual value

$$
E_{0}=V_{0}-D_{0}
$$

When allowing for different repayment agreements, the present value of the expected dividends is

$$
\begin{aligned}
V D_{0}=\sum_{t=1}^{T} \int_{t-1}^{t^{-}} E_{0}^{\prime}\left(D i v_{\tau}\right) \cdot e^{-r \cdot \tau} d \tau \\
\quad=\sum_{t=1}^{T} \int_{t-1}^{t^{-}} q \cdot E_{0}^{\prime}\left(V_{\tau} \mid \text { No Default until } t-1\right) \cdot e^{-r \cdot \tau} d \tau
\end{aligned}
$$


This can be simplified to

$$
V D_{0}=V_{0} \cdot\left(e^{q}-1\right) \sum_{t=1}^{T}\left[e^{-q t} \cdot N_{t-1}\left(d_{1}^{e x, 1}, \ldots, d_{1}^{e x, t-1} ; \rho_{t-1}\right)\right]
$$

where

$$
d_{1}^{e x, \tau}=\frac{\ln \left(\frac{V_{0}}{V_{T-\tau}^{*}}\right)+\left(r-q+\frac{\sigma_{V}^{2}}{2}\right) \cdot \tau}{\sigma_{V} \cdot \sqrt{\tau}}
$$

and

$$
d_{2}^{e x, \tau}=d_{1}^{e x, \tau}-\sigma_{V} \cdot \sqrt{\tau} .
$$

The killing prices $V_{\tau}^{*}$ for each period are calculated recursively ensuring that the boundary

$$
E_{\tau^{+}}\left(V_{\tau}^{*}\right)=I_{\tau}+P_{\tau}
$$

where

$$
V_{T}^{*}=I_{T}+P_{T}
$$

is fulfilled (see previous sections).

The value of the firm ex dividend, $V_{0}^{\text {ex }}$, is again the difference between the value of the firm without dividend payments, $V_{0}$, and the present value of the expected dividends.

$$
\begin{aligned}
V_{0}^{e x} & =V_{0}-V_{0}\left(e^{q}-1\right) \sum_{t=1}^{T} e^{-q t} \cdot N_{t-1}\left(d_{1}^{e x, 1}, \ldots, d_{1}^{e x, t-1} ; \rho_{t-1}\right) \\
& =V_{0}\left[1-\left(1-e^{-q}\right) \sum_{t=1}^{T} e^{-q(t-1)} \cdot N_{t-1}\left(d_{1}^{e x, 1}, \ldots, d_{1}^{e x, t-1} ; \rho_{t-1}\right)\right]
\end{aligned}
$$

The value of the firm's overall debt at $t=0$ is

$$
\begin{aligned}
& D_{0}=V_{0}^{e x}\left[1-N_{T}\left(d_{1}^{e x, 1}, \ldots, d_{1}^{e x, T} ; \rho_{T}\right)\right]+\sum_{t=1}^{T}\left(I_{t}+P_{t}\right) e^{-r \cdot t} \cdot N_{t}\left(d_{2}^{e x, 1}, \ldots, d_{2}^{e x, t} ; \rho_{t}\right) \\
& =V_{0}\left[1-\left(1-e^{-q}\right) \sum_{t=1}^{T} e^{-q(t-1)} \cdot N_{t-1}\left(d_{1}^{e x, 1}, \ldots, d_{1}^{e x, t-1} ; \rho_{t-1}\right)\right] \cdot\left[1-N_{T}\left(d_{1}^{e x, 1}, \ldots, d_{1}^{e x, T} ; \rho_{T}\right)\right] \\
& +\sum_{t=1}^{T}\left(I_{t}+P_{t}\right) e^{-r \cdot t} \cdot N_{t}\left(d_{2}^{e x, 1}, \ldots, d_{2}^{e x, t} ; \rho_{t}\right)
\end{aligned}
$$




\subsection{Multiple Debt Instruments}

Since we allow not only for different payback agreements but also for multiple debt instruments within one firm, we are also interested in determining the value of a specific debt instrument. For this, we once again use $\gamma$ to express the relation between the specific debt instrument under consideration and the total debt. The value of the specific debt instrument when the firm pays continuous dividends to the equity holders is

$$
\begin{aligned}
D_{0}^{S}=V_{0}^{e x} & {\left[\gamma_{1}+\sum_{t=1}^{T-1}\left(\gamma_{t+1}-\gamma_{t}\right) \cdot N_{t}\left(d_{1}^{1, e x}, \ldots, d_{1}^{t, e x} ; \rho_{t}\right)-\gamma_{T} \cdot N_{T}\left(d_{1}^{1, e x}, \ldots, d_{1}^{T, e x} ; \rho_{T}\right)\right] } \\
& +\sum_{t=1}^{T}\left(I_{t}^{S}+P_{t}^{S}\right) e^{-r \cdot t} \cdot N_{t}\left(d_{2}^{1, e x}, \ldots, d_{2}^{t, e x} ; \rho_{t}\right) \\
=V_{0} & {\left[1-\left(1-e^{-q}\right) \sum_{t=1}^{T} e^{-q(t-1)} \cdot N_{t-1}\left(d_{1}^{e x, 1}, \ldots, d_{1}^{e x, t-1} ; \rho_{t-1}\right)\right] } \\
& {\left[\gamma_{1}+\sum_{t=1}^{T-1}\left(\gamma_{t+1}-\gamma_{t}\right) \cdot N_{t}\left(d_{1}^{1, e x}, \ldots, d_{1}^{t, e x} ; \rho_{t}\right)-\gamma_{T} \cdot N_{T}\left(d_{1}^{1, e x}, \ldots, d_{1}^{T, e x} ; \rho_{T}\right)\right] } \\
& +\sum_{t=1}^{T}\left(I_{t}^{S}+P_{t}^{S}\right) e^{-r \cdot t} \cdot N_{t}\left(d_{2}^{1, e x}, \ldots, d_{2}^{t, e x} ; \rho_{t}\right)
\end{aligned}
$$

\subsection{Numerical Example}

We present a final numerical example illustrating the influence of dividends on the valuation of debt. For this, we once again use the firm we initially introduced in Section 2.6. The total assets amount to 100 and consist of a single debt instrument as well as

\begin{tabular}{|c|c|c|c|c|}
\hline Continuous dividend payment rate $\mathrm{q}$ & $0 \%$ & $1 \%$ & $2 \%$ & $3 \%$ \\
\hline Value of risk-free debt $\mathrm{D}_{0}^{\text {riskless }}$ & 70.58 & 70.58 & 70.58 & 70.58 \\
\hline Value of risky debt $\mathrm{D}_{0}^{\text {risky }}$ & 70.24 & 69.79 & 69.25 & 68.60 \\
\hline
\end{tabular}
equity. As in the initial example, the debt instrument is a lump sum loan with a nominal value of 70 , annual interest payments of $2.5 \%$, and a maturity of five years. In contrast to the first example, however, the equity holders now receive continuous dividends on the equity capital. All other parameters remain unchanged (see Table 1).

Table 5 provides and overview on how different continuous dividend payment rates influence the value of risky debt. The value of the risk-free debt at $t=0$ is not influenced by the dividend payments since the calculation assumes that there is no risk of default. As can be seen from the table, the present value of the risky debt decreases with an increase in the continuous dividend payment rate. This is due to the fact that the dividends are paid out of the assets of the firm. The higher the dividend, the higher is the reduction of the asset and, in consequence, the lower is the value available to the debtholders in case of bankruptcy. 


\section{Summary and Concluding Remarks}

In this paper, we contribute to the literature on the valuation of risky debt by providing three multivariate extensions of the standard Merton model. First, we lay forth an approach to pricing risky debt irrespective of its interest payment structure and the specified redemption agreement. We provide repayment-specific closed-form solutions as well as a generic formula with which debt instrument with any kind of interest payment structure and repayment specification can be valued. Furthermore, we provide formulas for the derivation of the cumulative, total, and conditional probabilities of default, the recovery rate, as well as the distance to default. We provide all insights for the risk-neutral investor as well as for risk-averse investors.

Second, we propose a technique for valuing multiple debt instruments within the same firm. We show that existing formulas for the valuation of debt cannot be applied to single debt instruments if the debt instrument is part of a debt portfolio. This is due to the fact that the default of one instrument in a debt portfolio has a direct impact on the other debt instruments in the portfolio. This interdependency diminishes the value of the other instruments and must therefore be incorporated into the valuation.

Third, we provide an approach for pricing one or more debt instruments with continuous dividend payments. We extend our generic formula for the valuation of debt instruments irrespective of their indenture specifications to account for the effect of continuous dividend payments to the equity holders. In this paper, we follow a nested approach in the sense that each subsequent model contains the preceding model as a special case.

We complement each section with a numerical example in order to make the theoretical model more tangible and highlight the easy-of-use of our model for practical applications. We generally advise financial practitioners to use our adapted formulas when valuing debt or for the calculation of default and recovery rates. The standard Merton model, whose application is still widespread in practice, can lead to inaccurate results, thus compromising the informative value of a valuation. Based on the formulas presented here, the accuracy of the valuation results can be improved.

Obviously, the model can be extended in several further dimensions. One potential avenue for future work could be the incorporation of a non-flat term structure as opposed to a constant risk-free interest rate. In this paper, we assume that the firm decides on the structure of its debt portfolio at $t=0$ and does not alter its composition until maturity. However, as Fischer and Wöckl (2019) suggest, it is meaningful for firms to evaluate the potential prepayment of existing debt instrument and refinance into new loans or bonds in order to take advantage of changes in the interest rate environment. The incorporation of such an evaluation into the models proposed here would require the departure from our assumption of a constant interest rate. Other models might instead incorporate a non-flat term structure to take such considerations into account. Another possible model extension is the inclusion of stochastic interest rates into the model. In this paper, we limit the constituents of the firm's debt portfolio to fixed-interest debt instruments by assuming a constant deterministic interest rate. However, Fischer and Kampl (2019) show that under certain circumstances, firms should prefer variable-rate debt instruments to fixed-rate debt. Other models may therefore incorporate stochastic interest rates to enable the valuation of variable-rate 
loans and bonds. Finally, other studies could investigate the effects of subordination arrangements on our formulas for the valuation of debt.

\section{References}

Anderson, R. W., and Sundaresan, S. (1996). Design and valuation of debt contracts. The Review of Financial Studies, 9(1), 37-68.

Black, F. and Cox, J.C. (1976). Valuing Corporate Securities: Some Effects of Bond Indenture Provisions. Journal of Finance, 31(2), 351-367.

Black, F. and Scholes, M. (1973). Firms of Options and Corporate Liabilities. Journal of Political Economy, 81(3), 637-654.

Bohn, J. R. (2000). A Survey of Contingent-Claims Approaches to Risky Debt Valuation. Journal of Risk Finance, 1(3), 53-70.

Fischer, E. O. and Kampl, L. (2019). How to Choose Between Fixed- and VariableRate Loans. Journal of Banking and Financial Research 67(2), 125-135.

Fischer, E. O., Keber, C. and Maringer, D. G. (2000). The valuation of credit guarantees by compound options (in German), OR-Spektrum, 22(4), 461-489.

Fischer, E. O. and Wöckl, I. (2019). Debt Restructuring: When Do Loan and Bond Prepayments Pay Off?. Journal of Banking and Financial Research, 67(1), 39-49.

Galai, D. and Wiener, Z. (2015). Credit Risk and Dividend Irrelevance, Working Paper, Hebrew University of Jerusalem.

Geske, R. (1977). The Valuation of Corporate Liabilities as Compound Options. Journal of Financial and Quantitative Analysis, 12(4), 541-552.

Geske, R. (1979). The Valuation of Compound Options. Journal of Financial Economics, 7(1), 63-81.

Geske, R. and Johnson, H. E. (1984). Valuation of Corporate Liabilities as Compound Options: A Correction. Journal of Financial and Quantitative Analysis, 19(2), 231-232.

Kim, I. J., Ramaswamy, K. and Sundaresan, S. M. (1993). The Valuation of Corporate Fixed-Income Securities. Financial Management, Special Issue on Financial Distress, Autumn, 117-131.

Longstaff, F. A. and Schwartz, E. S. (1995). A Simple Approach to Valuing Risky Fixed and Floating Rate Debt. Journal of Finance, 50 (3), 789-819.

Merton, R. C. (1973). An Intertemporal Capital Asset Pricing Model. Econometrica, 41(5), 867-887.

Merton, R. C. (1974). On the Pricing of Corporate Debt: The Risk Structure of Interest Rates. Journal of Finance, 29(2), 449-470. 
Saunders, A. and Allen, L. (2010). Credit risk management in and out of the financial crisis: new approaches to value at risk and other paradigms, Wiley, Hoboken, NJ.

Sundaram, R. K. and Das, S. (2009). Fixed Income and Credit Derivatives, McGraw Hill, London. 